\title{
Fertility and female wages: a new link via house prices*
}

\begin{abstract}
The analysis in this paper explains a new link between fertility and female wages that occurs through the effect of house prices. It is well known that higher female wages have an ambiguous effect on fertility: the positive income effect is offset by a negative substitution effect due to the higher opportunity cost of the maternal time required for child-rearing. Here it is shown that housing costs add a new dimension to this relationship. If the housing needs of children are a sufficiently important cost of child-rearing, then other costs of child rearing such as the opportunity cost of maternal time are rendered relatively less important. Hence the negative substitution effect of higher female wages on fertility is weaker, implying that higher female wages are more likely to boost fertility. This effect is stronger when the housing supply elasticity is high since house prices, and hence the costs of children, are kept in check. The analysis here helps to reconcile empirical observations about fertility, female wages and house prices in a number of countries. For governments concerned about low fertility, policies to increase housing supply elasticity in order to keep house prices in check would be helpful.

Keywords: Endogenous fertility, House prices, Gender wages, Working-age populations.
\end{abstract}

\footnotetext{
${ }^{*}$ The helpful comments and suggestions of anonymous referees and the editors Sushanta Mallick and Stephen George Hall are gratefully acknowledged.
} 


\section{Introduction}

The analysis in this paper connects two streams of literature on fertility. One is the wellestablished literature on the effect of economic growth on fertility. This effect is ambiguous a priori given that children are a normal good (Black et al., 2013), since higher household wages make children more affordable but raise the opportunity cost of maternal time. The negative opportunity cost effect, or substitution effect, is stronger the more that economic growth raises female wages relative to male wages (Barro and Becker, 1988; Cigno and Rosati, 1996; Galor and Weil, 1996). This literature has been extended to show that the substitution effect is weakened if households can substitute paid child care for maternal time (Apps and Rees, 2004; Day, 2004; Martinez and Iza, 2004; following Galor and Weil, 1996). Similarly, government-funded child care allowances unambiguously raise fertility (Yasuoko and Gotto, 2011; Ishida et al, 2015). The purpose of this paper is to explore how fertility responds to rising female relative wages if other cots of child rearing are taken into account. The particular cost here is housing costs of children.

The case for incorporating housing costs into models of endogenous fertility is strong. Housing costs comprise a greater portion of annual childrearing costs than do childcare or education (Lino, 2014). And intuitively, household decisions about having children and housing expenditure are made jointly, since children require housing as well as other implicit and explicit costs. ${ }^{1}$

In analyzing the role of housing costs the model here also connects with the literature on the links between demography and house prices, the early examples being Mankiw and Weil (1989) and Poterba (1991). A recent stream of empirical papers shows that rising house prices are associated with declining fertility in some high income countries but rising fertility in others. Yi and Zhang (2010) find that high house prices account for approximately 65 per cent of fertility decline in Hong Kong. Pan and Xu (2012) find a strong negative correlation between house prices and urban fertility in China. Also, countries where home ownership is most difficult also have the lowest fertility (McDonald, 2008; Mulder and Billari, 2010; Ost, 2012). On the other hand, Dettling and Kearney (2014) find a 10 per cent increase in house prices in the United States has led to a 4 per cent increase in births among home owners and a 1 per cent decrease among non-owners. And Lovenheim and Mumford (2013) find house price increases have a positive wealth effect on the fertility of existing home owners. The ambiguity of this empirical literature on the relationship between house prices and fertility suggests the need for analytical support from endogenous fertility modelling, as noted by others (McDonald, 2008; Malmberg, 2010). The endogenous fertility model here provides such a contribution.

The analysis here has potentially important policy implications, since it provides a better understanding of both the determinants of fertility and the effects of rising house prices. Persistent low fertility remains a concern for policy makers in many advanced economies. Referring to Figure 1, high income Asian economies continue to experience below replacement total fertility rates, whereas the total fertility rate is climbing back to replacement rate in Australia, France, United Kingdom and United States. Recent evidence suggests that economic development can reverse fertility decline when it is accompanied by increasing gender equality and opportunities for women to combine work with family life (Luci-Greulich and Thevenon, 2014). This accords with analysis that gender inequity explains low fertility in Asia (McDonald, 2008). The analysis in this paper offers a complementary explanation for fertility upturn in some developed economies and persistently low

\footnotetext{
${ }^{1}$ An important cost is high quality education. Economic growth raises the relative return to education per child, encouraging households to choose fewer but better educated children (Becker et al, 1990). Developing the model in this paper to incorporate a child quantity-quality tradeoff is an interesting direction for future research.
} 
fertility in others through the contribution of house prices to the cost of childrearing.

Figure 2 plots the real house price index for the same countries as in Figure 1. House prices increased significantly in the two decades prior to the global financial crisis in all countries except

Japan. As Figure 1 shows, during the same period the long run decline in fertility halted and indeed reversed for some countries (Australia, France, United Kingdom and United States), while it continued its downward trend for other countries (Hong Kong, Singapore and Japan). Hong Kong and Singapore have witnessed the steepest rise in real house prices over the last decade, with strong appreciations since the depth of the global financial crisis in late 2008. Our model shows how the fertility behavior of both groups of countries can be consistent with their house price trends, underpinned by growth in wages and working age populations. Figure 3 shows that working age population shares of total population have held up in most countries over the period, except for Japan where demographic pressure existed until the mid 1990s. Working age population shares are highest in Hong Kong and Singapore, with Hong Kong experiencing a particularly strong recent peak.

The core result from the analytical model developed in this paper can be explained intuitively as follows. Households' fertility decisions are affected by female wages both positively - as the income supports the cost of children - and negatively as the female's income imposes an opportunity cost on child-rearing time. However, if the housing needs of children are a sufficiently important cost of child-rearing, then the opportunity cost of maternal time becomes less important. In that case the negative effect of higher female wages on fertility is weaker, implying that higher female wages are more likely to boost fertility. This relationship is more complicated in the case of a growing economy, in particular driven by a rise in the working age population share. In this case, housing costs of children, which depend on current house prices, expected future prices and real lending rates, are important. Depending on the elasticity of housing supply, house prices may be bid up and the costs of children may rise which tends to lower fertility. All of this suggests that fertility decline depends on the gender wage gap, home lending rate and working age population share. The theoretical results are supported by econometric estimation of an error correction model for the illustrative case of Japan.

Section 2 of the paper provides the household intertemporal optimizing model used to analyze the effect of rising female relative wages and house prices on fertility. Section 3 models the determination of house prices in a market for housing with housing supply price elasticity. Section 4 provides a qualitative analysis of fertility decline under endogenous house prices and an econometric estimation for the case of Japan.

\section{Model}

The model here builds on analytical models in Deaton and Laroque (2001) and Garino and Sarno (2004) which explain rising house prices in a household optimization framework. Deaton and Laroque (2001) is a two period, constant population growth model and Garino and Sarno (2004) is a three period, fixed population model. These models are extended by linking house prices to fertility through the effect of female relative wages.

Consider an economy where people live for four periods. There are four generations alive at any given time: children, young age working households, middle age working households and old age households. Children consume maternal time and housing provided by their parents. The young working age household consumes and saves for a deposit to purchase housing, with which they rear children in middle age. The treatment of housing parallels the treatment of capital in the sense 
that capital must be saved for in middle age, but yields a return in retirement. Housing must be saved for in young age, but yields a return in middle age when it is used to rear children. ${ }^{2}$

The middle aged household consumes, rears children, repays a mortgage and saves for retirement. On retiring, the household funds old age consumption through the sale of the house and interest on saved capital. By implication, if young households are being forced to save more because of rising housing prices, then retiring households will consume a capital gain.

Each household derives utility directly from the number of children. Housing is a childrearing input and therefore a derived demand. The basic unit of analysis is the couple and they are assumed to be together from birth as in Galor and Weil (1996). The household is headed by a man and woman with joint consumption and utility. Each household has identical lifetime preferences.

The periods of young, middle aged and retired adulthood are denoted $t=0,1,2$, respectively. For a person who is young in period 0 , lifetime utility to be maximized is

$$
U=u\left(c_{0}\right)+\delta\left[u\left(c_{1}, n\right)\right]+\delta^{2} u\left(c_{2}\right)
$$

where $c_{t}$ and $n$ denote household consumption and pairs of children, respectively, and $\delta=1 /(1+\rho)$ is the discount rate with a constant time preference parameter, $\rho$. Individuals do not own housing in the first period of adulthood. As in Deaton and Laroque (2001), we may think of young working adults as living with their parents. Similarly, as in Garino and Sarno (2004), there is no utility from children or housing in old age.

Each agent is endowed with a unit of time. Men allocate their unit time endowment to the paid labor force. To raise children, women employ a fraction of their time endowment, $\hat{z} \in(0,1)$, in which case their paid labor supply is $(1-\hat{z} n)$. Women and men receive real wages of $w_{t}^{m}$ and $w_{t}^{f}$, respectively, in young and middle age $t=0,1$. Income for a young and middle aged household is therefore $w_{0}^{m}+w_{0}^{f}$ and $w_{1}^{m}+w_{1}^{f}(1-\hat{z} n)$, respectively.

Housing yields child rearing services and enters the child rearing cost function Working age households buy $\hat{h}$ units of housing per pair of children, so that each household demands $\hat{h} n$ units (square metres) of housing. Working age households purchase housing from newly retired households at the market price, $p_{1}^{h}$. Newly retired households at $t=2$ sell housing to the next generation of working age households at the market price, $p_{2}^{h}$. The market price at time $t, p_{t}^{h}$, is endogenously determined so that aggregate housing demand coincides with aggregate housing supply, which in turn is affected by the working age population ratio.

\subsection{Utility Maximization}

A young working age household faces the budget constraints

$$
\begin{aligned}
c_{0}+D_{0} & =w_{0}^{m}+w_{0}^{f} \\
c_{1}+\left(1+v_{1}\right)\left(p_{1}^{h} \hat{h} n-D_{0}\right)+w_{1}^{f} \hat{z} n+s_{1} & =w_{1}^{m}+w_{1}^{f} \\
c_{2} & =\left(1+r_{2}\right) s_{1}+p_{2}^{h} \hat{h} n
\end{aligned}
$$

when young, middle aged and retired at $t=0,1,2$, respectively. ${ }^{3}$ The mortgage size is $\left(p_{1}^{h} \hat{h} n-D_{0}\right)$ where the deposit $D_{0}$ is optimally chosen be the young working age household. The mortgage

\footnotetext{
${ }^{2}$ We can distinguish two forms of savings: housing savings used to purchase a house and financial savings which augment income in retirement (Creedy et al, 2015).

${ }^{3}$ All variables are real, with the price of aggregate consumption normalized to 1.
} 
repayment in middle age is $\left(1+v_{1}\right)\left(p_{1}^{h} \hat{h} n-D_{0}\right)$ where $v_{1}$ is the real mortgage interest rate. On retiring, the household sells their house and receives the prevailing real interest rate, $r_{2}$, on the amount of capital saved in middle age, $s_{1}{ }^{4}$

The utility functions are of $\log$ linear form,

$$
\begin{aligned}
u\left(c_{0}\right) & =\ln c_{0} \\
u\left(c_{1}, n\right) & =\beta \ln c_{1}+(1-\beta) \ln n \\
u\left(c_{2}\right) & =\ln c_{2}
\end{aligned}
$$

where $(1-\beta) \in(0,1)$ captures the relative preference for children, and satisfy strict concavity of $U($.$) , so that the optimally chosen quantities of fertility and consumption are expected to be strictly$ positive and female relative wages will have a strictly negative effect on fertility where maternal time is the only childrearing input (Galor and Weil, 1996, Apps and Rees, 2004).

Referring to the appendix, for a given childrearing input mix, $\hat{h}$ and $\hat{z}$, the household chooses fertility

$$
n=\frac{\delta(1-\beta)\left[\left(w_{1}^{f}+w_{1}^{m}\right) /\left(1+v_{1}\right)+\left(w_{0}^{m}+w_{0}^{f}\right)\right]}{[1+\delta(1+\delta)] p^{n} /\left(1+v_{1}\right)}
$$

which is increasing in the present value of lifetime wages, $\left(w_{1}^{f}+w_{1}^{m}\right) /\left(1+v_{1}\right)+\left(w_{0}^{m}+w_{0}^{f}\right)$, and decreasing in the per unit cost of rearing children, $p^{n}=\left[\left(\left(1+v_{1}\right) p_{1}^{h}-\frac{p_{2}^{h}}{\left(1+r_{2}\right)}\right) \hat{h}+w_{1}^{f} \hat{z}\right]>0$, which in turn depends on the optimal child rearing input mix.

\subsection{Cost minimization}

The total cost of rearing children is

$$
C=\pi\left(p_{1}^{h}, p_{2}^{h}, v_{1}, r_{2}\right) h+w_{1}^{f} z
$$

where $h=\hat{h} n, z=\hat{z} n$ and $\pi()=.\left(\left(1+v_{1}\right) p_{1}^{h}-p_{2}^{h} /\left(1+r_{2}\right)\right)$ is the user cost of housing, which is increasing in $p_{1}^{h}$ and decreasing in $p_{2}^{h}$. We herein explain that $p_{t}^{h}$ is determined by equilibrium in the market for housing. In equilibrium, the user cost is strictly positive $\pi()>$.0 , otherwise the demand for housing would be unbounded. However, as house prices rise, the user cost may fall if the increase in $p_{2}^{h}$ relative to $p_{1}^{h}, d p_{2}^{h} / d p_{1}^{h}>\left(1+v_{1}\right)\left(1+r_{2}\right)$, is sufficiently large.

The household chooses the input mix, for a given $n$, to minimize (4) subject to the child rearing production function,

$$
n=z^{\alpha} h^{1-\alpha}
$$

where $z$ and $h$ denote total time input and units of housing, respectively, and $\alpha \in(0,1)$ captures the relative importance of housing and time in childrearing. The production function is Cobb-Douglas where maternal time and housing are essential childrearing inputs. ${ }^{5}$

\footnotetext{
${ }^{4}$ The interest rate earned on saving for retirement, $r_{2}$, and paid on the outstanding housing debt, $v_{1}$, can differ due to tax rules and risk. All wages are after-tax in this model.

${ }^{5}$ Alternatively, we could postulate a CES production function, whereby maternal time is non-essential and the household may buy out maternal time for a childcare fee. Developing the model along these lines, however, would not overturn the results in this paper since, in a market equilibrium, childcare fees increase with the cost of unpaid time (Yasuoka and Miyake, 2010).
} 
Referring to the appendix, the input demands for housing and time are, respectively,

$$
\begin{aligned}
& h=\hat{h} n=\left(\frac{1-\alpha}{\alpha}\right)^{\alpha}\left(\frac{w_{1}^{f}}{\pi}\right)^{\alpha} n \\
& z=\hat{z} n=\left(\frac{\alpha}{1-\alpha}\right)^{1-\alpha}\left(\frac{\pi}{w_{1}^{f}}\right)^{1-\alpha} n
\end{aligned}
$$

and the optimal per unit cost of childrearing is

$$
p^{n}=a\left(w_{1}^{f}\right)^{\alpha}\left(\left(1+v_{1}\right) p_{1}^{h}-\frac{p_{2}^{h}}{\left(1+r_{2}\right)}\right)^{1-\alpha}
$$

where $a=\alpha^{-\alpha}(1-\alpha)^{-(1-\alpha)}$ and $p^{n}$ is strictly increasing and concave, which means that the input demands are positive and downward sloping. The user cost of housing, $\pi$, could be negative if $p_{2}^{h}$ is sufficiently large: $p_{2}^{h}>\left(1+r_{2}\right)\left(1+v_{1}\right) p_{1}^{h}$. However, the assumption $\alpha \in(0,1)$, which implies that child rearing requires shares of housing and time, rules out this possibility. Referring to equations (6a) and (6b), under this assumption, $\pi<0$ would imply $h<0$ and $z<0$. However, women's paid labor supply, $(1-z)$, cannot exceed the time endowment of 1 and, by equation (5), $z=0$ is not feasible because time and housing are essential for $n>0$.

\subsection{Optimal fertility for exogenous price of housing}

From (3) and (7), household demand for children is

$$
n=\frac{\delta(1-\beta)\left[\frac{\left(w_{1}^{f}+w_{1}^{m}\right)}{\left(1+v_{1}\right)}+\left(w_{0}^{m}+w_{0}^{f}\right)\right]}{[1+\delta(1+\delta)] a\left(\frac{w_{1}^{f}}{\left(1+v_{1}\right)}\right)^{\alpha}\left(p_{1}^{h}-\frac{p_{2}^{h}}{\left(1+r_{2}\right)\left(1+v_{1}\right)}\right)^{1-\alpha}}
$$

the key properties of which are summarized in the following remarks.

Remark 1 For given house prices, demand for children may rise with female relative wages if housing comprises a sufficiently large share of childrearing.

Referring to the appendix, fertility rises unambiguously in male wages. If fertility also rises with female wages, then fertility rises as female wages rise relative to male wages. Referring to the appendix, fertility is more likely to increase with female wages, the higher: the share of housing in childrearing, female relative wages, and present value of middle age female wages relative to young household male and female wages.

The intuitive explanation for a positive response of fertility demand to female relative wages lies in a comparison of substitution and income effects. To see this, consider the special case where maternal time is the only childrearing input $(\alpha=1)$. Referring to the appendix, in this case, fertility unambiguously declines with rising female relative wages. Intuitively, when both husband and wife work, female wages constitute a portion of household income. When maternal time is the only childrearing input, the cost of childrearing rises proportionately to female wages. As female relative wages rise, the substitution effect dominates the income effect and fertility declines. 
However, when both maternal time and housing are childrearing inputs, the cost of childrearing rises less than proportionate to female wages. A rise in female relative wages has competing effects on the demand for children. On the one hand, the increase in household wages makes children more affordable. On the other hand, children are more costly to raise using maternal time. The larger the intensity with which housing is used in childrearing, the smaller the effect of rising female wages on the marginal cost of childrearing. The income effect of rising female wages now dominates the substitution effect and fertility rises. Empirical evidence indicates that housing comprises the largest share of childrearing (Lino, 2014). Thus, we can infer that demand for children would indeed rise with female relative wages, for given house prices.

Remark 2 If the user cost of housing falls with rising house prices, then demand for children increases, all else equal.

From (8), fertility is decreasing in $p_{1}^{h}$, and increasing in $p_{2}^{h} /\left(1+r_{2}\right)\left(1+v_{1}\right)$. Intuitively, children are a normal good. Housing is used to rear children. On the one hand, an increase in current house prices reduces the fertility of a young household that is saving for a deposit. On the other hand, a young household also realizes that the family home is a means of storing and transferring wealth from working age to retirement. Thus, an increase in the discounted value of future house prices has a positive wealth effect on the demand for children. ${ }^{6}$ This is consistent with evidence that rising house prices reduces the fertility of non-home owners and increases the fertility of home owners via a wealth effect (Lovenheim and Mumford (2013)). If future house prices increase relative to current house prices such that the user cost of housing falls, then the wealth effect dominates and fertility rises.

Thus far the effect of rising female relative wages on fertility has been analyzed for given house prices, $p_{1}^{h}$ and $p_{2}^{h}$. By (6a), rising female wages also increase demand for housing per child. At the individual household level, the household may take house prices as given. However, at the the aggregate level, house prices are endogenous. We now endogenize house prices by assuming that housing is bought at a price determined by market demand and supply.

\section{Housing Market}

From (6a) and (8), the final demand for housing by a working age household is

$$
h_{1}=\frac{\delta(1-\beta)(1-\alpha)\left[\frac{\left(w_{1}^{f}+w_{1}^{m}\right)}{\left(1+v_{1}\right)}+\left(w_{0}^{m}+w_{0}^{f}\right)\right]}{[1+\delta(1+\delta)]\left[p_{1}^{h}-\frac{p_{2}^{h}}{\left(1+r_{2}\right)\left(1+v_{1}\right)}\right]}
$$

which is increasing in household preference for children, $(1-\beta)$, the share of housing in childrearing, $(1-\alpha)$, the present value of lifetime wages and decreasing in the user cost of housing.

The expression for demand for housing services may be generalized to

$$
h_{t}^{d}=\frac{\delta(1-\beta)(1-\alpha)\left[\frac{\left(w_{t}^{f}+w_{t}^{m}\right)}{\left(1+v_{t}\right)}+\left(w_{t-1}^{m}+w_{t-1}^{f}\right)\right]}{[1+\delta(1+\delta)]\left[p_{t}^{h}-\frac{E_{t} p_{t+1}^{h}}{\left(1+E_{t} r_{t+1}\right)\left(1+v_{t}\right)}\right]}
$$

\footnotetext{
${ }^{6}$ It is worth noting that the capital gain from sale of the family home in $t=2$ is not a pure wealth windfall, since parents implicitly revert to rental accommodation which is included in $c_{2}$ and rents increase with house prices. Extending the model to include an endogenous price of rental accomodation is an interesting direction for future research.
} 
where, under rational expectations, $E_{t}($.$) are conditional expectations of the variable based on$ information available at time $t$.

Housing has intrinsic value through childrearing. There are $L_{t}^{w}$ working age households purchasing housing and $L_{t}^{o}$ retired households that are selling housing to the new young working age households. Under perfect competition, housing sells for the same market price at which the older generation is selling housing.

Aggregate demand for housing at time $t$ is

$$
h_{t}^{d} L_{t}^{w}=\frac{\delta(1-\beta)(1-\alpha)\left[\frac{\left(w_{t}^{f}+w_{t}^{m}\right)}{\left(1+v_{t}\right)}+\left(w_{t-1}^{m}+w_{t-1}^{f}\right)\right]}{[1+\delta(1+\delta)]\left[p_{t}^{h}-\frac{E_{t} p_{t+1}^{h}}{\left(1+E_{t} r_{t+1}\right)\left(1+v_{t}\right)}\right]} L_{t}^{w}
$$

Equation (11) suggests a feedback loop between fertility and house prices. By (8), for given house prices, demand for children may increase as female wages rise relative to male wages. Demand for housing increases with male and female wages, which in turn puts pressure on house prices to rise. One possibility is that wages growth simply results in higher house prices. Referring again to (8), an increase in the contemporary house price raises the user cost of housing. This in turn reduces fertility. The effect of increasing aggregate demand for housing on the market price will obviously depend on the housing supply elasticity. We herein introduce a finite elasticity supply function (Guest, 2005).

The aggregate supply of housing is

$$
h_{t}^{s}=\frac{b\left(p_{t}^{h}\right)^{\psi}}{(1+N)} L_{t}^{w} \text { where } b>0, \psi \geq 0
$$

where $b$ is a shift variable that represents factors that influence housing supply other than price. In the special case where supply of housing is price inelastic $(\psi=0), b$ denotes an exogenous supply of housing that may be increased due to government land release policy for example. $N$ is growth in the working age population: $L_{t}^{w}=(1+N) L_{t}^{o}=(1+N) L_{t-1}^{w}$.

The market price of housing is determined so that aggregate demand coincides with aggregate supply. Equating (11) and (12) yields the equilibrium condition

$$
\left[p_{t}^{h}-\frac{E_{t} p_{t+1}^{h}}{\left(1+E_{t} r_{t+1}\right)\left(1+v_{t}\right)}\right]\left(p_{t}^{h}\right)^{\psi}=\frac{\delta(1-\beta)(1-\alpha)}{[1+\delta(1+\delta)]} \frac{(1+N)}{b} y_{t}
$$

where $y_{t}=\left(w_{t-1}^{m}+w_{t-1}^{f}\right)+\left(w_{t}^{f}+w_{t}^{m}\right) /\left(1+v_{t}\right)$ denotes the present value of lifetime wages. Equation (13) says that $p_{t}^{h}$ is an implicit function of $E_{t} p_{t+1}^{h}, y_{t}$ and $(1+N) .{ }^{7}$ Referring to the appendix,

$$
\begin{aligned}
\frac{\partial p_{t}^{h}}{\partial E_{t} p_{t+1}^{h}} & >0 ; \frac{\partial^{2} p_{t}^{h}}{\partial\left(E_{t} p_{t+1}^{h}\right)^{2}} \leq 0 \\
\frac{\partial p_{t}^{h}}{\partial y_{t}} & >0 ; \frac{\partial^{2} p_{t}^{h}}{\partial\left(y_{t}\right)^{2}} \leq 0 \\
\frac{\partial p_{t}^{h}}{\partial(1+N)} & >0 ; \frac{\partial^{2} p_{t}^{h}}{\partial(1+N)^{2}} \leq 0
\end{aligned}
$$

\footnotetext{
${ }^{7}$ An implication of the partial equilibrium nature of the model is that $N$ does not affect market wages for males or females, hence $N$ cannot affect fertility through $w^{m}$ or $w^{f}$.
} 
where the second order derivatives hold with strict inequality for $\psi>0 .^{8}$

Intuitively, housing demand from working age households is downward sloping or decreasing in the user cost of housing, which is increasing in the current price and decreasing in the discounted expected future price. Increases in the present value of lifetime wages shift out demand for housing, which is derived from demand for children, a normal good. An rise in the ratio of working age households to retired households increases housing demand which increases price. Housing supply from retired households is upward sloping or increasing in the current price. Thus, a rise in the support ratio raises the market price.

High wages, expected future prices and working age to elderly population ratios all put pressure on the market price of housing. Some elasticity in supply dampens the price increase. When supply is perfectly price inelastic, the second order derivatives in (14) are zero. We summarize this discussion with the following remark.

Remark 3 The market price of housing is increasing and strictly concave in the expected future price, present value of lifetime wages and the support ratio. For a perfectly price inelastic supply of housing, the market price of housing is increasing and concave in these variables.

We characterize the behavior of $p_{t}^{h}$ that obeys equation (13) in order to analyze the impact of speculative demand on the endogenous determination of house prices. To solve explicitly for $p_{t}^{h}$, we consider the case where housing supply is price inelastic $(\psi=0)^{9}$ and assume rational expectations. From equation (13),

$$
p_{t}^{h}=\frac{1}{a_{t}} E_{t} p_{t+1}^{h}+c y_{t}
$$

where $a_{t}=\left(1+E_{t} r_{t+1}\right)\left(1+v_{t}\right)$ and $c=[\delta(1-\beta)(1-\alpha)(1+N)] / b[1+\delta(1+\delta)]$. Referring to the appendix, using the law of iterated expectations and solving recursively yields

$$
p_{t}^{h}=\prod_{i=0}^{T} E_{t} \frac{1}{a_{t+i}} p_{t+T+1}^{h}+c \sum_{i=0}^{T} E_{t} y_{t+i} \prod_{i=1}^{T} E_{t} \frac{1}{a_{t+i-1}}
$$

where $T$ is the time horizon of the household. The term $\prod_{i=0}^{T} E_{t} \frac{1}{a_{t+i}} p_{t+T+1}^{h}$ captures expected house price appreciation which is central to the existence of a bubble (Feng and $\mathrm{Wu}, 2015)$. Referring to the appendix,

$$
p_{t}^{h}=c \sum_{i=0}^{\infty} E_{t} y_{t+i} \prod_{i=1}^{\infty} E_{t} \frac{1}{a_{t+i-1}}
$$

is a solution, which gives the price of housing as the present discounted value of expected future income.

Although equation (17) is a solution to equation (15), it is not the only solution. Relaxing the condition that the expected house prices will not explode too fast, equation (15) has a general solution of the form

$$
p_{t}^{h}=p_{t}^{h *}+B_{t}
$$

${ }^{8}$ If $\psi=0$, then equation (13) provides an explicit solution, $p_{t}^{h}=\frac{E_{t} p_{t+1}^{h}}{E_{t}\left(1+r_{t+1}\right)\left(1+v_{t}\right)}+\frac{\delta(1-\beta)(1-\alpha)}{[1+\delta(1+\delta)]} \frac{(1+N)}{\bar{h}} y_{t}$.

${ }^{9}$ Equation (13) is a non-linear expectational difference equation when $\psi>0$. 
where $p_{t}^{h *}$ denotes the solution given by equation (17). Referring to the appendix, for positive real interest and lending rates, $B_{t}$ explodes in expected value

$$
\lim _{t \rightarrow \infty} E_{t} B_{t+1}= \begin{cases}+\infty & \text { if } B_{t}>0 \\ -\infty & \text { if } B_{t}<0\end{cases}
$$

where several examples of $B_{t}$ processes show that $B_{t}$ embodies speculative bubbles. ${ }^{10}$. Thus, while $p_{t}^{h *}$ is the fundamental solution, $B_{t}$ is called a speculative bubble. Intuitively, in a model with infinitely lived households who are forward looking and have perfect foresight, $B_{t}$ ought to equal zero under rational expectations. However, in our model, a speculative bubble may arise in equilibrium under rational expectations because households who make no bequests and sell housing to fund retirement consumption have finite horizons. Thus, our model captures speculative demand and bubbles as a driving force of rising house prices. As current prices and expected future prices rise, the effect on fertility depends on the housing cost of children, which the following section recognizes is endogenously determined by housing supply, household wages and working age population share.

\section{Equilibrium}

We herein analyze how fertility responds to female relative wages and the working age population ratio under endogenous house prices. Substituting for $p_{t}^{h}-E_{t} p_{t+1}^{h} /\left(1+E_{t} r_{t+1}\right)\left(1+v_{t}\right)$ in (8) from (13), fertility is

$$
n=\left[\frac{\alpha(1-\beta) y\left(w_{1}^{f}, w_{1}^{m}, w_{0}^{f}, w_{0}^{m}\right) \delta}{\left(\frac{w_{1}^{f}}{\left(1+v_{1}\right)}\right)[1+\delta(1+\delta)]}\right]^{\alpha}\left[\frac{b\left\{p_{1}^{h}\left(p_{2}^{h},(1+N), y(.)\right)\right\}^{\psi}}{(1+N)}\right]^{1-\alpha}
$$

where $y=\left[\frac{\left(w_{1}^{f}+w_{1}^{m}\right)}{\left(1+v_{1}\right)}+\left(w_{0}^{m}+w_{0}^{f}\right)\right]$.

The focus of the analysis does not deny the importance of other factors. Along with the market price of housing, the price per living area also affects fertility (Sato, 2007; Simon and Tamura, 2009). Moreover, metropolitan area commuting times are negatively associated with labor force participation rates of married women with children (Black et al, 2014). We can address spatial analysis in the model by adjusting the exogenous supply of housing space, $b$. Referring to (6a), each working household demands $\hat{h} n$ square meters of housing. That is, households who want to have more children, $n$, prefer larger houses. In urban locations, where space is limited, $b$ would be lower. Referring to (13) and (20), price per square meter would be higher and fertility would be lower, all else equal. Thus, it would take sharp declines in overall prices to incentivize increased fertility in urban locales where $b$ remains low, and thus price per square meter and cost of the daily commute between home and workplace remain high. Conversely, increased fertility may be easier to incentivize in rural locations where space is plentiful.

\subsection{Qualitative analysis}

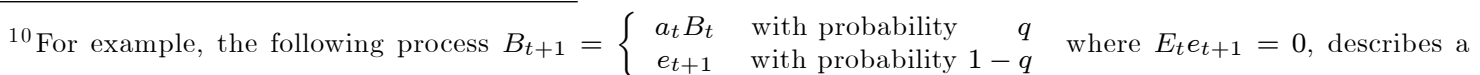
bursting bubble. The bubble continues with probability $q$ or bursts and returns in expected value to zero with probability $1-q$.
} 
Referring to the appendix,

$$
\begin{aligned}
& \frac{\partial \ln n}{\partial \ln w_{1}^{f}}\left\{\begin{array}{cc}
>0 & \text { if } \psi>\frac{\alpha}{(1-\alpha)}\left[\left(\frac{\partial \ln p_{1}^{h}}{\partial \ln \left(w_{1}^{f} / y\right)}\right)^{-1}\right] \\
<0 & \text { if } \psi=0
\end{array}\right. \\
& \frac{\partial \ln n}{\partial \ln (1+N)}\left\{\begin{array}{cc}
<0 & \text { if } \psi<\left(\frac{\partial \ln p_{1}^{h}}{\partial \ln (1+N)}\right)^{-1} \\
<0 & \text { if } \psi=0
\end{array}\right.
\end{aligned}
$$

where the first condition of (21a) says that fertility is more likely to rise with female wages if the price elasticity of housing supply $(\psi)$ is high, the share of housing in child rearing $(1-\alpha)$ is high and the elasticity of house prices with respect to female wages relative to household wages is low. The second condition of (21a) says that fertility unambiguously declines with female wages if housing supply is perfectly price inelastic.

Equation (20) reveals that a contemporaneous increase in female wages relative to male wages impacts fertility in three respects. First, an increase in $w_{1}^{f}$ and $w_{1}^{m}$ increases $y$, which has a positive income effect on demand for children. Second, an increase in $w_{1}^{f}$ increases the opportunity cost of maternal time, which has a negative substitution effect on the demand for children. Third, the increase in demand for housing, brought about by an increase in $y$ raises the market price, $p_{1}^{h}$, which in turn induces a positive housing supply response if $\psi>0$.

In the special case where housing supply is perfectly price inelastic $(\psi=0)$, we observe only the first two effects. Fertility unambiguously declines with an increase in $w_{1}^{f} / w_{1}^{m}$. Intuitively, household wages rise less than proportionately to female wages while the cost of maternal time rises proportionately to female wages. Accordingly, the negative substitution effect of rising female wages outweighs the positive income effect and fertility declines.

To demonstrate the role of endogenous house prices, it is helpful to compare the result from equation (20) that $n$ declines with an increase in $w_{1}^{f} / w_{1}^{m}$ for endogenous house prices when $\psi=0$, with the result from equation (8) that $n$ declines with an increase in $w_{1}^{f} / w_{1}^{m}$ for exogenous house prices, only if housing's share of childrearing, $(1-\alpha)$, is sufficiently large. Fertility rises with $w_{1}^{m}$, but the effect of an increase in $w_{1}^{f}$ on fertility is ambiguous for exogenous house prices. Referring to (8), an increase in $w_{1}^{f}$ raises both household wages, $y$, and the opportunity cost of maternal time. The cost of child rearing comprises the opportunity cost of maternal time, $w_{1}^{f}$, weighted by $\alpha$, and the user cost of housing $\left(p_{1}^{h}-p_{2}^{h} /\left(1+r_{2}\right)\left(1+v_{1}\right)\right)$, weighted by $(1-\alpha)$. For an exogenous user cost of housing, an $x \%$ increase in $w_{1}^{f}$ raises $y$ by less than $x \%$ and the cost of rearing each child pair by $\alpha x \%$. The overall effect of increase in $w_{1}^{f}$ on $n$ is positive only if $\alpha$ is sufficiently low.

For endogenous house prices, the effect of an increase in $w_{1}^{f}$ on fertility is unambiguously negative when $\psi=0$. Referring to equation (13), the user cost of housing now increases proportionately to $y$ in a market equilibrium. Intuitively, an increase in $y$ raises demand for housing, which in turn raises $p_{1}^{h}$ relative $p_{2}^{h}$. Referring to equation (8), a less than $x \%$ increase in the user cost of housing raises the cost of child rearing by less than $(1-\alpha) x \%$. Household wages relative to housing childrearing costs therefore increase by less than $\alpha x \%$. The increased cost of maternal time raises the cost of child rearing by $\alpha x \%$. The latter effect more than outweighs the former. Hence, fertility declines unambiguously with an increase in $w_{1}^{f}$.

We now consider the case where there is some price elasticity in housing supply. By equation (13), in equilibrium the user cost of housing is decreasing in housing supply, which now responds 
positively to an increase in $p_{1}^{h}$, brought about by an increase in $p_{2}^{h},(1+N)$ or $y$. The housing supply response to an increase in $y$ will dampen the increase in $p_{1}^{h}$, and hence the rise in the user cost of housing. This explains the third positive effect of an increase in $y$ on fertility when housing supply is increasing in $p_{1}^{h}$. In the presence of this third effect, it is possible for fertility to rise with female wages if the price elasticity of housing supply is sufficiently high to satisfy the first inequality in (21a).

The first condition of $(21 \mathrm{~b})$ says that a rise in the support ratio, $(1+N)$,will reduce fertility if the price elasticity of housing supply $(\psi)$ is less than the inverse of the elasticity of house prices with respect to the support ratio. Intuitively, the less responsive is housing supply to an increase in $p_{1}^{h}$, the more the increased housing demand brought about by an increase in $(1+N)$ feeds through to an increase in $p_{1}^{h}$, which reduces fertility. The second condition of (21b) follows from the result that when $\psi=0$ the equilibrium the user cost of housing, $\left(p_{1}^{h}-p_{2}^{h} /\left(1+r_{2}\right)\left(1+v_{1}\right)\right)$, increases proportionately to $(1+N)$. An increase in the user cost of housing raises the cost of childrearing, thereby reducing fertility.

The following remark summarizes our discussion of the effect of female relative wages and working age to retired population ratios on fertility when house prices are endogenously determined in a market where housing supply is either fixed or price responsive.

Remark 4. For endogenous house prices, fertility

i. may increase with female relative wages if the price elasticity in supply is sufficiently high relative to the share of maternal time in childrearing and the elasticity of price with respect to female wages as a portion of household wages;

ii. declines unambiguously as female relative wages rise if housing supply is fixed;

iii. declines as the working age population ratio increases if the price elasticity of supply is less than the inverse of the elasticity of house prices with respect to the working age population ratio.

Whereas gender wage gaps remain high in Japan, gender wage gaps in Hong Kong and Singapore compare with the OECD average. Despite ranking among countries with the lowest fertility in the world, Hong Kong and Singapore experience above average population growth for high income economies. International migrant stock now approximates 39 percent and 38 percent of the total population in Hong Kong and Singapore, respectively, which is more than three times the average for high income economies (World Bank, 2014). ${ }^{11}$ Immigration of working age adults ameliorates the pace of ageing, but places pressure on housing constraints. There are approximately 8.3 and 5.9 persons of working age per elderly in Hong Kong and Singapore, respectively. Remark 4 suggests that, all else equal, house prices would be highest in Hong Kong and Singapore, which is indeed the case.

[Table 1 about here]

\subsection{Empirical illustration}

An empirical model for Hong Kong confirms the results of our intertemporal analysis. Yi and Zhang (2010) use an Error Correction Model (ECM) to estimate the effect on the total fertility rate $(T F R)$ of real house prices, female wages and male wages for the period, 1971-2005. They find that

\footnotetext{
${ }^{11}$ International migrant stocks approximate 10 percent and 14 percent of the total population in the United Kingdom and the United States, respectively.
} 
the coefficient on house prices is significant and implies a long run elasticity of $T F R$ with respect to house prices of -0.45 . The coefficient on female wages is negative, but statistically insignificant at the 10 per cent level. They infer that, holding house prices constant, demand for children need not decline with female wages because the substitution effect of female wages does not dominate the income effect. This is consistent with Remark 1.

However, our intertemporal analysis goes further by explaining that house prices are endogenously determined. Remarks 1 and 2 explain that female wages relative to male wages and house prices affect demand for children. House prices are in turn affected by growth in household wages and the working age population. This suggests an empirical model of fertility with explanatory variables that avoid the problems of endogeneity in house prices and multicollinearity between wages and house prices. Remark 4 provides a reduced form equation for fertility

$$
T F R_{t}=n_{t}\left(\left(\frac{w_{f}}{w_{m}}\right)_{t}, N_{t}, v_{t}\right)
$$

where $\partial n / \partial\left(w_{f} / w_{m}\right)<0, \partial n / \partial(1+N)<0$ and $\partial n / \partial(1+v)>0$ when the housing supply is price inelastic. Equation (22) may be viewed as an equilibrium or cointegrating relationship.

Whereas female and male median hourly wages currently differ by around 17 percent in Hong Kong, the gender gap in median hourly wages in Japan is currently around 28 per cent. ${ }^{12}$ However, Japan's female to male median hourly wages have increased from 59.2 per cent to 72.2 percent over the period, 1980 to 2012. The above analysis explains the persistence of fertility decline despite rising female relative wages, because growth in wages and the working age population raise the user cost of housing, which in turn depresses fertility since housing is used to rear children.

The dynamic representation of equation (22) may be given by the following Error Correction Model (ECM)

$$
\Delta T F R_{t}=a+\phi_{i} \Delta X_{i t}+\lambda T F R_{t-1}+b_{i} X_{i t-1}+e_{t}
$$

where $X_{i}$ are the explanatory variables in our reduced form equation $(22),\left(w^{f} / w^{m}\right)_{t}, N_{t}$, and $v_{t}, \lambda$ is the error correction coefficient which determines the speed of adjustment, and $e_{t}$ is the error term. All variables entering the model are in logarithmic form. This allows us to interpret elasticities to confirm the results from the qualitative analysis.

As an illustrative example, we estimate equation (23) for Japan, 1980-2012. The variables $n_{t},\left(w^{f} / w^{m}\right)_{t}, N_{t}$ and $v_{t}$ are measured by annual data on $T F R$, median hourly female wages relative to median hourly wages, percentage of population aged 15-59 years (WAPOP) and the long term prime lending interest rate adjusted for inflation as measured by the GDP deflator $(L L R)$, respectively (World Bank, 2014, Statistics Japan, 2015).

If two or more $I(1)$ variables are cointegrated, that is, if there exists a linear combination of the non-stationary variables that is stationary, then a long run relationship suggested by the reduced form equation (22) exists. The mechanism that drives the variables to their long-run relationship is captured by equation (23) in which the equilibrium error also drives the dynamics of the series.

[Table 2 about here]

Table 2 reports the results of the augmented Dickey-Fuller (ADF) tests for the four series. Following the standard recommendation (Hamilton, 1994), we run the tests for the general model with both a time trend and a constant and for the specific model without a time trend. Referring to

${ }^{12}$ Calculations based on 2013 hourly wage data from http://www.censtad.gov.hk/ and http://www.e-stat.go.jp/. 
Table 2, the test statistics are insignificant at the 5 per cent level. Therefore, we do not reject the null hypothesis that each series exhibits a unit root. The results of the unrestricted cointegration test indicate the presence of at least one cointegrating equation between the four variables. The Trace Statistic (P-value) is 49.81 (0.004) and Maximum Eigenvalue Statistic (P-value) is 27.46 (0.017). Therefore, we can reject the null hypothesis of no cointegration between the variables at the 5 per cent level. The existence of a cointegrating vector means that the equilibrium relationship among the nonstationary series can be uniquely identified.

[Table 3 about here]

The estimated long run elasticities of $T F R$ with respect to the explanatory variables from (23) are reported in the upper panel of Table 3 . The estimated error correction coefficient, $\hat{\lambda}$, suggests a plausible speed of adjustment of -0.45 and is significant at the 1 per cent level, supporting the evidence of co-integration. The estimated coefficients for $w^{f} / w^{m}$ and WAPOP are significant at the 5 and 1 per cent level, respectively, and imply long run elasticities of $T F R$ with respect to female relative wages and the working age population ratio that are negative and of similar magnitude. These elasticity estimates are consistent with our theoretical prediction that fertility is decreasing in female relative wages and the working age population ratio in an economy where housing supply price elasticity is low. The estimated coefficient for $L L R$ implies a positive long run elasticity of $T F R$ with respect to the home loan lending interest rate, also consistent with our intertemporal analysis, but the coefficient is only significant at 5 per cent level, using a one-sided test.

While estimating the reduced form equation (23) for other high income economies is outside the scope of this paper, the estimates for Japan suggest interesting implications for existing and future empirical work. Referring to Figure 1, Japan and Hong Kong witnessed similar TFR decline over the period 1980-2012. However, referring to Figure 2, Japan's house prices started declining in the mid-1990s. Hong Kong house prices rose steeply until the late 1990s, then fell until the mid-2000s, before rising again. Over the period 1970-2005, house prices in Hong Kong exhibited more of an upward trend throughout, which our model explains could contribute to $T F R$ decline if current prices rise relative to expected future prices, thereby raising housing costs of children. The negative trend in house prices in Japan over 1980-2012 could also raise housing costs of children if expected future prices fall relative to current prices. Our model explains that housing costs of children are endogenous and that $T F R$ depends on the gender wage gap, working age population ratio and real lending rate, as shown by equation (23). Nonetheless, given the differences between Hong Kong and Japan, we scrutinize our empirical estimates more closely with diagnostic tests.

[Table 4 about here]

Table 4 reports the diagnostic tests for serial correlation, heteroskedasticity, and nonnormality of the residuals. First, the Breusch-Godfrey Lagrange Multiplier (LM) test statistic is insignificant (P-value 0.578$)$, indicating that we do not reject the null hypothesis of no serial correlation in the residuals. Second, the LM test for Autoregressive Conditional Heteroskedasticity (ARCH) in the residuals identifies a dynamic form of heteroskedasticity where the magnitude of residuals is related to the magnitude of recent residuals. This test can identify when large or small errors tend to occur in clusters. The Breusch-Pagan test may detect more general forms of heteroskedasticity. Both the ARCH and the Bresuch-Pagan LM test statistics are insignificant ( $\mathrm{P}$ value 0.429 and 0.997, respectively). Finally, the Jarque-Bera test statistic is also insignificant (P-value 0.757), indicating that we do not reject the null hypothesis that the residuals are normally distributed. Thus, the 
diagnostic tests indicate that there is no significant presence of serial correlation, heteroskedasticity and nonnormality.

\section{Conclusion}

The analysis in this paper connects two streams in the literature on fertility modelling and in doing so helps to reconcile different observed relationships between fertility and house prices in some Asian countries. The analysis shows that house prices can affect fertility by mediating the effect of female wages on fertility. The key idea is that the well-known negative substitution effect of rising female wages on fertility depends on how important housing is as a cost of children, and on what is happening to house prices as a rising working age population puts upward pressure on housing demand. It turns out that the negative substitution effect on fertility is weaker the more important housing is as a cost of children.

In countries where the price elasticity of housing supply is low, as in some Asian countries, the model predicts that rising female wages at the same time as rising housing demand may result in lower fertility. For example, Japan's proportionate decline in fertility was largest between 1980 and the early 1990s, when a high working age population ratio correlated with rising real house prices. In Hong Kong and Singapore, where recently the proportional increase in the working age population ratio has been large and price elasticity of housing supply is low, we would expect fertility decline to continue. In other developed economies, such as Australia, where housing supply is relatively price elastic and parents place a premium on homeownership, we would expect fertility decline to reverse with rising female relative wages and house prices.

For governments concerned about low fertility, policies to increase housing supply elasticity in order to keep house prices in check would be helpful. This is all the more important for countries where housing demand is rising due to a rising working age population share, and conversely, less important for countries where housing demand is weaker. In the context of Japan, the empirical estimates of our model suggest that demographic pressure on house prices contributed to past fertility decline. Looking forward, the current and future demographic trend of a shrinking working age population ratio points to rising female wages as the more important factor in fertility decline. This provides an interesting focus for future research.

\section{References}

Apps, P., Rees, R., 2004. Fertility, taxation and family policy. Scandinavian Journal of Economics 106, 745-73.

Barro, R., Becker, G., 1988. A reformulation of the economic theory of fertility. The Quarterly Journal of Economics CIII, 1-25.

Becker, G., Murphy, K., Tamura, R. 1990. Human capital, fertility and economic growth. Journal of Political Economy 98, 12-37.

Black, D., Kolesnikova, N., Sanders, S., Taylor, L., 2013. Are children normal? Review of Economics and Statistics 95, 21-33.

Black, D., Kolesnikova, N., Taylor, L., 2014. Why do so few women work in New York (and so many in Minneapolis)? Labor supply of married women across US cities. Journal of Urban Economics 79, 59-71.

Cigno, A., Rosati, F., 1996. Jointly determined saving and fertility behavior: Theory and estimates for Germany, Italy, UK and USA. European Economic Review 40, 1561-89. 
Creedy, J., Gemmell, N., Scobie, G., 2015. Pensions, savings and housing: A life-cycle framework with policy simulations. Economic Modelling 46, 346-57.

Day, C., 2004. The dynamics of fertility and growth: Baby boom, bust and bounce-back. Topics in Macroeconomics 4, 1-32.

Dettling, L., Kearney, M., 2014. House prices and birth rates: the impact of the real estate market on the decision to have a baby. Journal of Public Economics 110, 82-100.

Deaton, A., Laroque, G., 2001. Housing, land prices, and growth. Journal of Economic Growth 6, $87-105$.

Federal Reserve Bank of Dallas. 2014. International House Price Dataset.

Feng, Q., Wu, G. L., 2015. Bubble or riddle? An asset-pricing approach evaluation on China's housing market. Economic Modelling 46, 376-83.

Galor, O., Weil, D., 1996. The gender gap, fertility and growth. The American Economic Review $86,374-87$.

Garino, G., Sarno, G., 2004. Speculative bubbles in UK house prices: Some new evidence. Southern Economic Journal 70, 777-95.

Guest, R., 2005. A life-cycle analysis of housing affordability options for first home owner-occupiers in Australia. Economic Record 81, 237-248.

Hamilton, J., 1994. Time Series Analysis. Princeton University Press, Princeton.

Ishida, R., Ogura, K., Takahata, J., 2015. Child benefit and fiscal burden in the endogenous fertility setting. Economic Modelling 44, 252-65.

Lino, M., 2014. Expenditures on children by families, 2013. U.S. Department of Agriculture, Centre for Nutrition Policy and Promotion, Miscellaneous Publication No. 1528-2013, August 2014.

Lovenheim, M., Mumford, K., 2013. Do wealth shocks affect fertility choice? Evidence from the housing market boom and bust. Review of Economics and Statistics 95, 464-475.

Luci-Greulich, A., Thevenon, O., 2014. Does economic advancement 'cause' a re-increase in fertility? European Journal of Population 30, 187-221.

Martinez, D., Iza, A., 2004. Skill premium effects on fertility and female labor force supply. Journal of Population Economics 17, 1-16.

Malmberg, B., 2010. Low fertility and the housing market: evidence from Swedish regional data. European Journal of Population 26, 229-44.

Mankiw, N. G., Weil, D., 1989. The baby boom, the baby bust and the housing market. Regional Science and Urban Economics 19, 235-58.

McDonald, P., 2008. Explanations of low fertility in Asia. in Ultra-low Fertility in Pacific Asia: Trends, causes and policy issues, edited by Straughan, P., Chan, A. and Jones, G., Taylor and Francis Group.

Mulder, C., Billari, F. 2010. Homeownership regimes and low fertility, Housing Studies 25, 527-41.

Ost, C., 2012. Housing and children: simultaneous decisions? - a cohort study of young adults' housing and family formation decision. Journal of Population Economics 25, 349-66.

Pan, L., Xu, J., 2012. Housing price and fertility rate. China Economic Journal 5, 97-111.

Poterba, J., 1991. House price dynamics: the role of tax policy and demography. Brookings Papers on Economic Activity 2, 143-203.

Sato, Y., 2007. Economic geography, fertility and migration. Journal of Urban Economics 61, 372387.

Simon, C., Tamura, R., 2009. Do higher rents discourage fertility? Evidence from U.S. cities, 19402000. Regional Science and Urban Economics 39, 33-42.

Statistics Japan. 2015. Basic Survey of Wage Structure, Statistics Bureau, Tokyo. 
United Nations 2015. World Population Prospects: The 2015 Revision. Department of Economic and Social Affairs, Population Division, New York.

World Bank 2014. World Development Indicators, World Bank, Washington D.C.

Yasuoka, M., Miyake, A., 2010. Change in the transition of the fertility rate. Economics Letters $106,78-80$.

Yasuoka, M., Goto, N., 2011. Pension and Child Care Policies with Endogenous Fertility. Economic Modelling 28, 2478-82.

Yi, J., Zhang, J., 2010. The effect of house prices on fertility: Evidence from Hong Kong. Economic Inquiry $48,635-50$. 


\section{Appendix}

\section{Utility maximization}

The inter-temporal household choice is determined by backward induction. At $t=1$, the household chooses $c_{1}$ and $c_{2}$ to maximize

$$
u\left(c_{1}, n\right)+\delta u\left(c_{2}(n)\right)
$$

subject to (1b) and (1c),

$$
c_{1}+\left(1+v_{1}\right)\left(p_{1}^{h} \hat{h} n-D_{0}\right)+w_{1}^{f} \hat{z} n+\frac{\left(c_{2}-p_{2}^{h} \hat{h} n\right)}{\left(1+r_{2}\right)}=w_{1}^{m}+w_{1}^{f}
$$

where past fertility, housing and deposit choice, $n, \hat{h} n$ and $D_{0}$, respectively, are given from $t=0$. Substituting for (2a) and (2b) in (A1.1), the maximization problem at $t=1$ is

$$
\max \beta \ln c_{1}+(1-\beta) \ln n+\delta\left(\ln c_{2}(n)\right)
$$

subject to (A1.2), rewritten as

$$
c_{1}+\left[\left(\left(1+v_{1}\right) p_{1}^{h}-\frac{p_{2}^{h}}{\left(1+r_{2}\right)}\right) \hat{h}+w_{1}^{f} \hat{z}\right] n-\left(1+v_{1}\right) D_{0}+\frac{c_{2}}{\left(1+r_{2}\right)}=w_{1}^{m}+w_{1}^{f}
$$

The optimality conditions imply

$$
\frac{c_{2}(n)}{c_{1}}=\frac{\left(1+r_{2}\right) \delta}{\beta}
$$

which substituted into (A1.4) give the optimal consumption in middle age and old age,

$$
\begin{aligned}
& c_{1}=\frac{\beta}{\beta+\delta}\left[w_{1}^{f}+w_{1}^{m}-p^{n} n+\left(1+v_{1}\right) D_{0}\right]=c_{1}\left(n, D_{0}\right) \\
& c_{2}=\frac{\delta}{\beta+\delta}\left(1+r_{2}\right)\left[w_{1}^{f}+w_{1}^{m}-p^{n} n+\left(1+v_{1}\right) D_{0}\right]=c_{2}\left(n, D_{0}\right)
\end{aligned}
$$

At $t=0$, the household chooses $c_{0}, D_{0}$ and $n$ to maximize

$$
u\left(c_{0}\right)+\delta\left[u\left(c_{1}\left(n, D_{0}\right), n\right)\right]+\delta^{2} u\left(c_{2}\left(n, D_{0}\right)\right)
$$

subject to (1a), (A1.6a) and (A1.6b). Substituting for (2a), (2b) and (2c) in (A1.7), the maximization problem at $t=0$ is

$$
\max \ln c_{0}+\delta\left[\beta \ln c_{1}\left(n, D_{0}\right)+(1-\beta) \ln n\right]+\delta^{2}\left(\ln c_{2}\left(n, D_{0}\right)\right)
$$

subject to (1a) and (A1.4). The first order optimality conditions give the optimal deposit for a housing loan

$$
D_{0}=\frac{\delta(1+\delta)\left(1+v_{1}\right)\left(w_{0}^{m}+w_{0}^{f}\right)-\left(w_{1}^{m}+w_{1}^{f}\right)}{[1+\delta(1+\delta)]\left(1+v_{1}\right)}
$$

which is increasing in the mortgage interest rate, $\partial D_{0} / \partial\left(1+v_{1}\right)>0$, and the optimal fertility for a given $p^{n}$,

$$
n=\frac{\delta(1-\beta)\left[\left(w_{1}^{f}+w_{1}^{m}\right) /\left(1+v_{1}\right)+\left(w_{0}^{m}+w_{0}^{f}\right)\right]}{[1+\delta(1+\delta)] p^{n} /\left(1+v_{1}\right)}
$$


Cost minimization

The household chooses $\mathrm{h}$ and $\mathrm{z}$ to minimize (4) subject to (5). The optimality conditions imply

$$
\frac{z}{h}=\frac{\pi}{w_{1}^{f}} \frac{\alpha}{1-\alpha}
$$

which substituted into (5) give the input demands (6a) and (6b). Substituting from (6a) and (6b) for $\hat{h}$ and $\hat{z}$ in $p^{n}=\left[\pi \hat{h}+w_{1}^{f} \hat{z}\right]$ gives the optimal per unit child rearing cost

$$
p^{n}=\alpha^{-\alpha}(1-\alpha)^{-(1-\alpha)}\left(w_{1}^{f}\right)^{\alpha}(\pi)^{1-\alpha}
$$

where

$$
\begin{aligned}
\frac{\partial p^{n}}{\partial w_{1}^{f}} & =\left(\frac{\alpha}{1-\alpha}\right)^{1-\alpha}\left(\frac{\pi}{w_{1}^{f}}\right)^{1-\alpha}=\hat{z}>0 \\
\frac{\partial p^{n}}{\partial \pi} & =\left(\frac{1-\alpha}{\alpha}\right)^{\alpha}\left(\frac{w_{1}^{f}}{\pi}\right)^{\alpha}=\hat{h}>0 \\
\frac{\partial^{2} p^{n}}{\partial\left(w_{1}^{f}\right)^{2}} & =\frac{\partial \hat{z}}{\partial w_{1}^{f}}<0 ; \frac{\partial^{2} p^{n}}{\partial \pi^{2}}=\frac{\partial \hat{h}}{\partial \pi}<0
\end{aligned}
$$

Proof of Remark 1

From (8),

$$
d \ln n=\frac{\partial \ln n}{\partial \ln w_{1}^{f}} d \ln w_{1}^{f}+\frac{\partial \ln n}{\partial \ln w_{1}^{m}} d \ln w_{1}^{m}-(1-\alpha) d \ln \pi
$$

where $\left(d \ln w_{1}^{f}-d \ln w_{1}^{m}\right)>0$ if female wages rise relative to male wages and

$$
\begin{aligned}
\frac{\partial \ln n}{\partial \ln w_{1}^{f}} & =\frac{w_{1}^{f}}{\left(1+v_{1}\right)\left(w_{0}^{m}+w_{0}^{f}\right)+\left(w_{1}^{f}+w_{1}^{m}\right)}-\alpha \gtreqless 0 \\
\frac{\partial \ln n}{\partial \ln w_{1}^{m}} & =\frac{w_{1}^{m}}{\left(1+v_{1}\right)\left(w_{0}^{m}+w_{0}^{f}\right)+\left(w_{1}^{f}+w_{1}^{m}\right)}>0
\end{aligned}
$$

By (A3.2b), fertility rises unambiguously in male wages. From (A3.2a), fertility rises with female wages when the following condition is met

$$
\frac{\partial \ln n}{\partial \ln w_{1}^{f}}>0 \Leftrightarrow \frac{(1-\alpha)}{\alpha}>\frac{\left(w_{0}^{m}+w_{0}^{f}\right)}{w_{1}^{f} /\left(1+v_{1}\right)}+\frac{w_{1}^{m}}{w_{1}^{f}}
$$

where $w_{1}^{m} / w_{1}^{f}>1$ if a gender wage gap exists and $(1-\alpha) / \alpha>1$ if housing is a greater portion of childrearing than maternal time $(\alpha<0.5)$. According to (A3.3), fertility is more likely to increase with female wages, the higher: the share of housing in childrearing, $(1-\alpha)$; female relative wages, 
$\left(w_{1}^{f} / w_{1}^{m}\right)$; and present value of middle age female wages relative to young male and female wages, $\left(w_{1}^{f} /\left(1+v_{1}\right)\right) /\left(w_{0}^{m}+w_{0}^{f}\right)$.

Referring to (A3.2a), if $\alpha=1$, then $\partial \ln n / \partial \ln w_{1}^{f}<0$, since middle age female wages are a fraction of the present value of lifetime wages, $w_{1}^{f}<\left(1+v_{1}\right)\left(w_{0}^{m}+w_{0}^{f}\right)+\left(w_{1}^{f}+w_{1}^{m}\right)$. Substituting for $\partial \ln n / \partial \ln w_{1}^{f}<0$ and $d \ln \pi=0$ in (A3.1), $d \ln n<0$ since $-w_{1}^{m}\left(d \ln w_{1}^{f}-d \ln w_{1}^{m}\right)-(1+$ $\left.v_{1}\right)\left(w_{0}^{m}+w_{0}^{f}\right) d \ln w_{1}^{f}<0$.

Proof of Remark 3

$$
F\left(p_{t}^{h}, E_{t} p_{t+1}^{h}, N, y_{t}\right)=\left[p_{t}^{h}-\frac{E_{t} p_{t+1}^{h}}{\left(1+E_{t} r_{t+1}\right)\left(1+v_{t}\right)}\right]\left(p_{t}^{h}\right)^{\psi}-\frac{\delta(1-\beta)(1-\alpha)}{[1+\delta(1+\delta)]} \frac{(1+N)}{b} y_{t}=0
$$

Using the implicit function theorem, $\partial p_{t}^{h} / \partial x=-F_{x} / F_{p_{t}^{h}}$, where $x=E_{t} p_{t+1}^{h},(1+N), y_{t}$ :

$$
\begin{aligned}
& \frac{\partial p_{t}^{h}}{\partial E_{t} p_{t+1}^{h}}=\frac{1}{\left[\left(1+E_{t} r_{t+1}\right)\left(1+v_{t}\right) p_{t}^{h}-E_{t} p_{t+1}^{h}\right] \psi\left(p_{t}^{h}\right)^{-1}+\left(1+E_{t} r_{t+1}\right)\left(1+v_{t}\right)}>0 \\
& \rightarrow \frac{1}{\left(1+E_{t} r_{t+1}\right)\left(1+v_{t}\right)}>0 \text { as } \psi \rightarrow 0 \\
& \frac{\partial p_{t}^{h}}{\partial y_{t}}=\frac{\frac{\delta(1-\beta)(1-\alpha)}{[1+\delta(1+\delta)]} \frac{(1+N)}{b}}{\left\{\left[p_{t}^{h}-\frac{E_{t} p_{t+1}^{h}}{\left(1+E_{t} r_{t+1}\right)\left(1+v_{t}\right)}\right] \psi\left(p_{t}^{h}\right)^{-1}+1\right\}\left(p_{t}^{h}\right)^{\psi}}>0 \\
& \rightarrow \frac{\delta(1-\beta)(1-\alpha)}{[1+\delta(1+\delta)]} \frac{(1+N)}{b}>0 \text { as } \psi \rightarrow 0 \\
& \frac{\partial p_{t}^{h}}{\partial(1+N)}=\frac{\frac{\delta(1-\beta)(1-\alpha)}{[1+\delta(1+\delta)]} \frac{y t}{b}}{\left\{\left[p_{t}^{h}-\frac{E_{t} p_{t+1}^{h}}{\left(1+E_{t} r_{t+1}\right)\left(1+v_{t}\right)}\right] \psi\left(p_{t}^{h}\right)^{-1}+1\right\}\left(p_{t}^{h}\right)^{\psi}}>0 \\
& \rightarrow \frac{\delta(1-\beta)(1-\alpha)}{[1+\delta(1+\delta)]} \frac{y_{t}}{b}>0 \text { as } \psi \rightarrow 0
\end{aligned}
$$

Proof of Remark 4

From equation (22), 


$$
\begin{aligned}
& \frac{\partial \ln n}{\partial \ln w_{1}^{f}}=\alpha\left(\frac{\partial \ln y}{\partial \ln w_{1}^{f}}-1\right)+(1-\alpha) \psi \frac{\partial \ln p_{1}^{h}}{\partial \ln y} \frac{\partial \ln y}{\partial \ln w_{1}^{f}} \\
& <0 \quad \text { if } \psi<\frac{\alpha}{(1-\alpha)}\left[\frac{1}{\frac{\partial \ln p_{1}^{h}}{\partial \ln w_{1}^{f}}}-\frac{1}{\frac{\partial \ln p_{1}^{h}}{\partial \ln y}}\right] \\
& \text { where } \frac{\partial \ln y}{\partial \ln w_{1}^{f}}<1 \Rightarrow[.]>0 \\
& <0 \text { if } \psi=0 \text { since } \frac{\partial \ln y}{\partial \ln w_{1}^{f}}<1 \\
& \frac{\partial \ln n}{\partial \ln (1+N)}=-(1-\alpha)\left[1-\psi \frac{\partial \ln p_{1}^{h}}{\partial \ln (1+N)}\right] \\
& <0 \text { if } \frac{1}{\psi}>\frac{\partial \ln p_{1}^{h}}{\partial \ln (1+N)} \\
& <0 \text { if } \psi=0 \text { since } 0<\alpha<1
\end{aligned}
$$

Derivation of equation (16)

Writing equation (15) at time $t+1$ and taking the expectations of both sides conditional on information at time $t$ yields

$$
E_{t} p_{t+1}^{h}=E_{t} \frac{1}{a_{t+1}} E_{t}\left(E_{t+1} p_{t+2}^{h}\right)+c E_{t} y_{t+1}
$$

Using the law of iterated expectations,

$$
E_{t} p_{t+1}^{h}=E_{t} \frac{1}{a_{t+1}} E_{t} p_{t+2}^{h}+c E_{t} y_{t+1}
$$

Replacing in (15) gives

$$
p_{t}^{h}=\frac{1}{a_{t}} E_{t} \frac{1}{a_{t+1}} E_{t} p_{t+2}^{h}+\frac{1}{a_{t}} c E_{t} y_{t+1}+c y_{t}
$$

Solving recursively up to time $T$,

$$
\begin{aligned}
p_{t}^{h}= & \frac{1}{a_{t}} E_{t} \frac{1}{a_{t+1}} \ldots E_{t} \frac{1}{a_{t+T}} E_{t} p_{t+T+1}^{h} \\
& +c \frac{1}{a_{t}} \ldots E_{t} \frac{1}{a_{t+T-1}} E_{t} y_{t+T} \\
& +\ldots+\frac{1}{a_{t}} c E_{t} y_{t+1}+c y_{t}
\end{aligned}
$$

which using summation and product notation, gives

$$
p_{t}^{h}=\prod_{i=0}^{T} E_{t} \frac{1}{a_{t+i}} p_{t+T+1}^{h}+c \sum_{i=0}^{T} E_{t} y_{t+i} \prod_{i=1}^{T} E_{t} \frac{1}{a_{t+i-1}}
$$


The transversality condition

$$
\lim _{T \rightarrow \infty} \prod_{i=0}^{T} E_{t} \frac{1}{a_{t+i}} E_{t} p_{t+T+1}^{h}=0
$$

means the expectation will not explode too fast. Assuming this condition, as $T \rightarrow \infty$,

$$
p_{t}^{h}=c \sum_{i=0}^{\infty} E_{t} y_{t+i} \prod_{i=1}^{\infty} E_{t} \frac{1}{a_{t+i-1}}
$$

Derivation of equation (19)

If $p_{t}^{h}=p_{t}^{h *}+B_{t}$, then $E_{t} p_{t+1}^{h}=E_{t} p_{t+1}^{h *}+E_{t} B_{t+1}$. Replacing $p_{t}^{h}$ and $E_{t} p_{t+1}^{h}$ in equation (15) implies that

$$
p_{t}^{h *}+B_{t}=\frac{1}{a_{t}} E_{t} p_{t+1}^{h *}+\frac{1}{a_{t}} E_{t} B_{t+1}+c y_{t}
$$

By the definition of $p_{t}^{h *}$ in (17),

$$
\begin{aligned}
p_{t}^{h *} & =c \frac{1}{a_{t}} \ldots E_{t} \frac{1}{a_{t-1+\infty}} E_{t} y_{t+\infty}+\ldots+\frac{1}{a_{t}} c E_{t} y_{t+1}+c y_{t} \\
E_{t} p_{t+1}^{h *} & =c E_{t} \frac{1}{a_{t+1}} \ldots E_{t} \frac{1}{a_{t+\infty}} E_{t} y_{t+1+\infty}+\ldots+c E_{t} y_{t+1}
\end{aligned}
$$

where substituting for $p_{t}^{h *}$ and $E_{t} p_{t+1}^{h *}$,

$$
\begin{aligned}
p_{t}^{h *}+B_{t} & =\frac{1}{a_{t}} E_{t} p_{t+1}^{h *}+\frac{1}{a_{t}} E_{t} B_{t+1}+c y_{t} \\
& \Rightarrow c \frac{1}{a_{t}} \ldots E_{t} \frac{1}{a_{t-1+\infty}} E_{t} y_{t+\infty}+\ldots+\frac{1}{a_{t}} c E_{t} y_{t+1}+c y_{t}+B_{t} \\
& =c \frac{1}{a_{t}} E_{t} \frac{1}{a_{t+1}} \ldots E_{t} \frac{1}{a_{t+\infty}} E_{t} y_{t+1+\infty}+\ldots+\frac{1}{a_{t}} c E_{t} y_{t+1}+c y_{t}+\frac{1}{a_{t}} E_{t} B_{t+1} \\
& \Rightarrow B_{t}=c \frac{1}{a_{t}} E_{t} \frac{1}{a_{t+1}} \ldots E_{t} \frac{1}{a_{t+\infty}} E_{t} y_{t+1+\infty}+\frac{1}{a_{t}} E_{t} B_{t+1} \\
& \Rightarrow B_{t}=\frac{1}{a_{t}} E_{t} B_{t+1}
\end{aligned}
$$

since $\frac{1}{a_{t}} E_{t} \frac{1}{a_{t+1}} \ldots E_{t} \frac{1}{a_{t+\infty}} \rightarrow 0$. Thus,

$$
B_{t}=\left(a_{t}\right)^{-1} E_{t} B_{t+1} \Leftrightarrow E_{t} B_{t+1}=\left(a_{t}\right)^{1} B_{t}
$$

where the assumption $a_{t}>1 \Leftrightarrow\left(1+E_{t} r_{t+1}\right)\left(1+v_{t}\right)>1$, is equivalent to assuming real interest and mortgage rates are positive. Note that since $a_{t}>1,\left(a_{t}\right)^{i} \rightarrow \infty$ as $i \rightarrow \infty$. Thus,

$$
\lim _{i \rightarrow \infty} E_{t} B_{t+i}=\left(a_{t}\right)^{i} B_{t}= \begin{cases}+\infty & \text { if } B_{t}>0 \\ -\infty & \text { if } B_{t}<0\end{cases}
$$




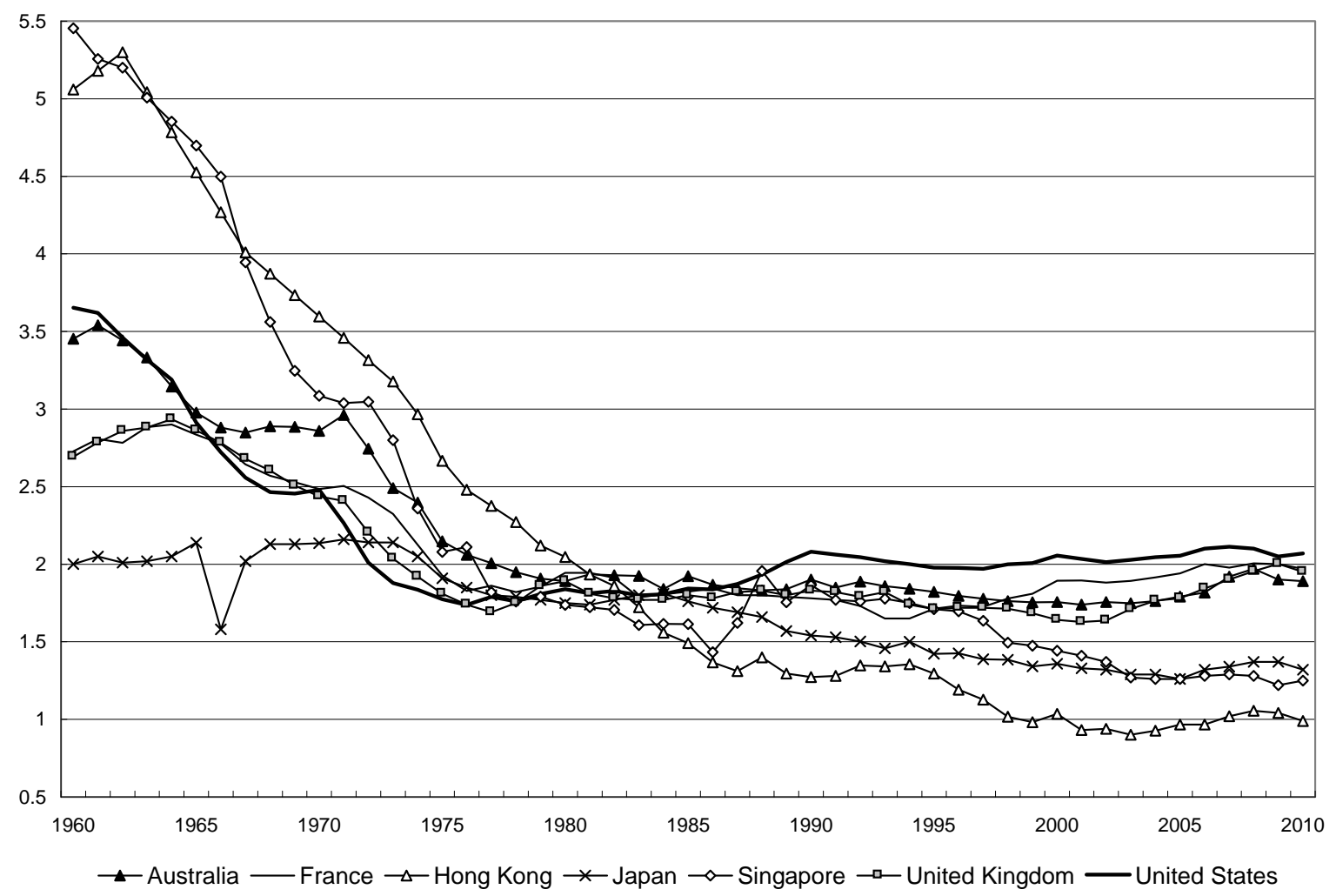

FIGURE 1

Total Fertility Rate (births per woman), 1960-2010 


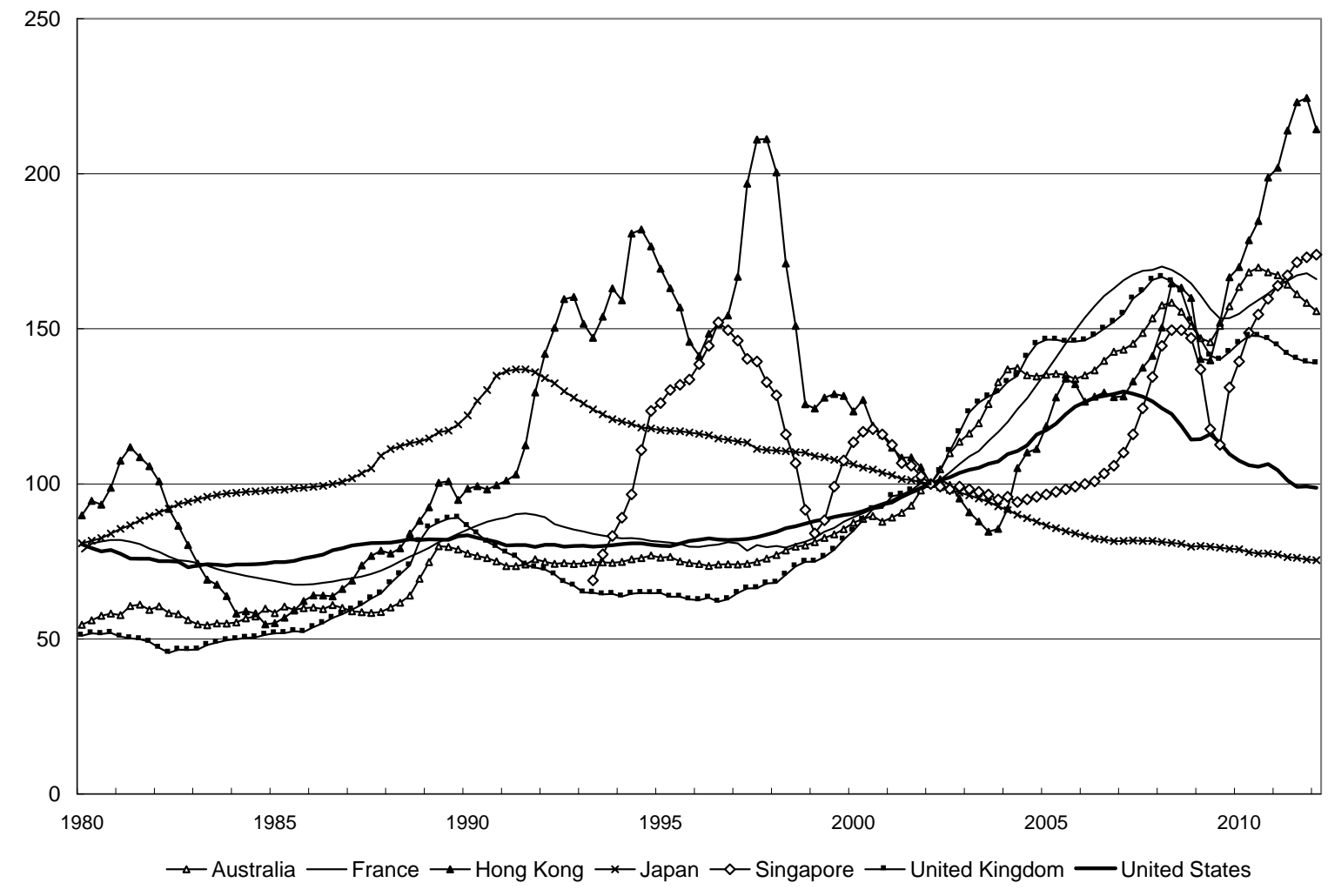

FIGURE 2

Real House Price Index, High Income Countries, 1980-2012

Source: Federal Reserve Bank of Dallas, National Sources 


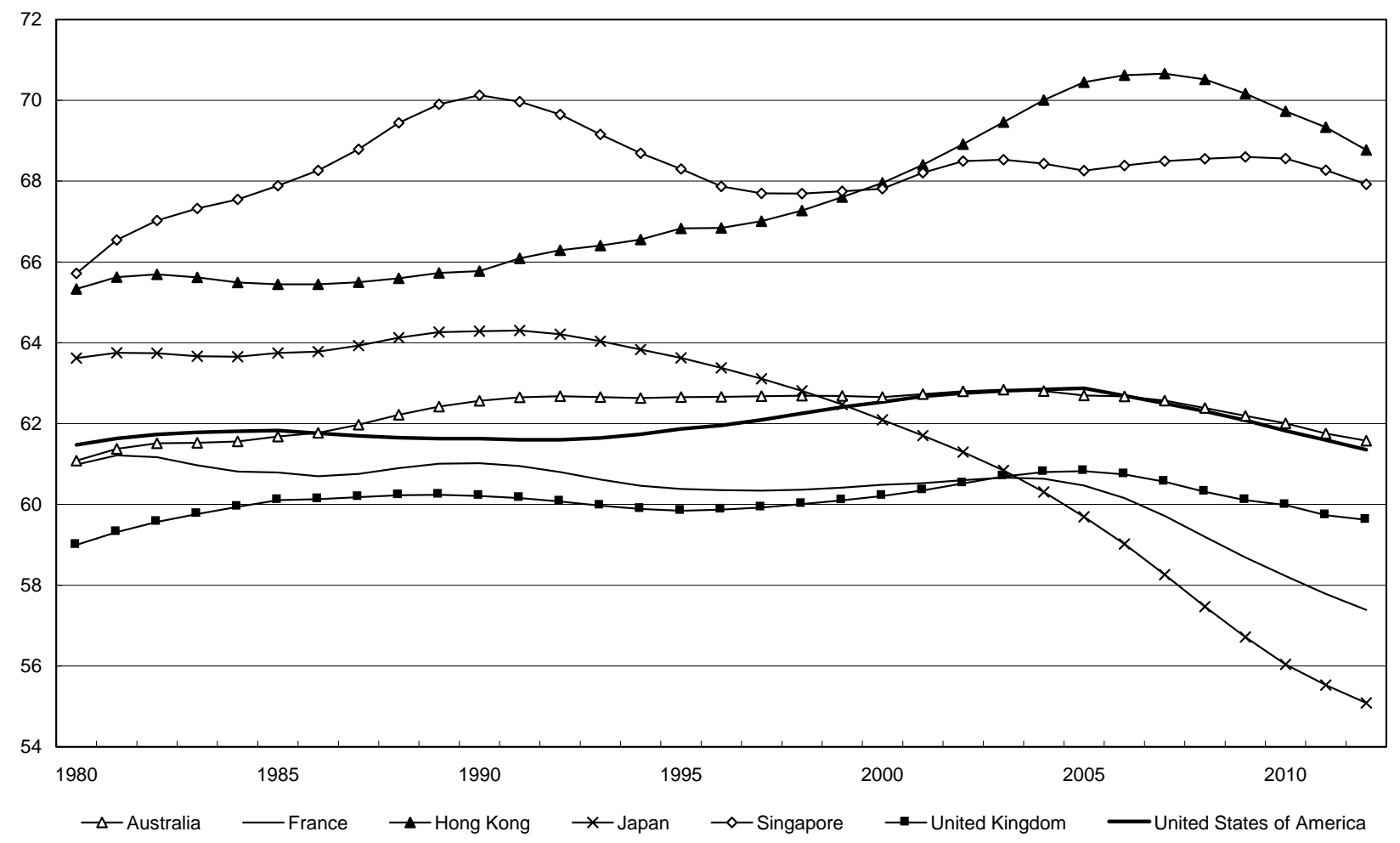

FIGURE 3

Working age population (percentage of population), 1980-2012

Source: United Nations (2015) 
TABLE 1

Population Support Ratios and Immigration

\begin{tabular}{lccc}
\hline Country & $\begin{array}{c}\text { Support Ratio } \\
(15-64 / 65+)\end{array}$ & $\begin{array}{c}\text { Population Growth } \\
\text { (average annual) } \\
(1990-2009)\end{array}$ & $\begin{array}{c}\text { Migrant Stock } \\
\text { \% population) }\end{array}$ \\
\hline Australia & 2010 & 1.3 & 2010 \\
France & 5 & 0.5 & 21.1 \\
Hong Kong & 3.9 & 1.1 & 10.6 \\
Japan & 5.9 & 0.2 & 38.9 \\
Singapore & 2.86 & 2.6 & 1.7 \\
United Kingdom & 8.33 & 0.4 & 38.3 \\
United States & 4 & 1.1 & 10.4 \\
High Income & 5 & 0.7 & 13.8 \\
\hline
\end{tabular}

Source: World Bank (2014) 
TABLE 2

Augmented Dickey Fuller Test Statistics for logarithm of variables

\begin{tabular}{lcccc}
\hline Variable & With trend & P-value & Without trend & P-value \\
\hline TFR & 0.269 & 0.998 & -1.44 & 0.550 \\
$W f / W m$ & -3.181 & 0.106 & 0.577 & 0.987 \\
$W A P O P$ & -1.478 & 0.810 & -0.774 & 0.809 \\
$L L R$ & -2.113 & 0.519 & -1.514 & 0.513 \\
\hline
\end{tabular}


TABLE 3

Estimates of Long run Elasticities and Speed of Adjustment in ECM

\begin{tabular}{|c|c|c|c|}
\hline Variable & Elasticity with respect to TFR & Standard Error & $\mathrm{P}$-value \\
\hline$W f / W m$ & $-2.935^{*}$ & 0.478 & 0.0118 \\
\hline$W A P O P$ & $-2.986^{* *}$ & 0.397 & 0.0028 \\
\hline$L L R$ & 0.017 & 0.006 & 0.2195 \\
\hline Speed of adjustment & $-0.447 * *$ & 0.155 & 0.0086 \\
\hline R-squared & $72.51 \%$ & Sample period: & $1980-2012$ \\
\hline Adjusted R-squared & $62.51 \%$ & Observations: & 33 \\
\hline
\end{tabular}

* Significant at the $5 \%$ level

**Significant at the $1 \%$ level 
TABLE 4

Diagnostic tests

\begin{tabular}{lll}
\hline & $\chi^{2}$ Statistic & P-value \\
\hline Breusch-Godfrey LM test for serial correlation & 1.098 & 0.578 \\
Breusch-Pagan test for heteroskedasticity & 1.124 & 0.997 \\
ARCH test for heteroskedasticity & 0.627 & 0.429 \\
Jarque-Bera Test for normality & 0.557 & 0.757 \\
\hline
\end{tabular}

